\title{
Disclosing Extra-Dyadic Involvement (EDI): Understanding Attitudes, Subjective Norms, and Perceived Behavioral Control
}

\author{
Ryan B. Seedall • Austin Houghtaling • Erica J. Wilkins
}

(C) Springer Science+Business Media New York 2013

\begin{abstract}
Extra-dyadic involvement (EDI) is a complex issue that affects many individuals, couples, and families. One important, relatively unexplored issue concerns the disclosure of EDI. Despite some scholarly discourse on whether disclosure should be facilitated in a therapeutic context (e.g., Butler et al. in J Marital Fam Ther 35:125-143, 2009; Butler et al. in Am J Fam Ther 36:265-283, 2008), empirical research has not studied the intrapersonal or interpersonal processes related to disclosure. In this study, we explored potential factors involved in the decision to disclose EDI by looking at the relationships among attitudes towards EDI (in terms of perceived justifications and costs), subjective norms (obligation to disclose), and perceived behavioral control (difficulty) associated with EDI disclosure. Our sample included 337 individuals enrolled in at least one university course at one of three geographically distinct universities. Findings indicate that more permissive attitudes towards EDI are not significantly associated to the perceived difficulty in disclosing EDI or the obligation associated with disclosing EDI involving sexual intercourse. However, more permissive attitudes are related to lower felt obligation to disclose EDI that does not involve direct sexual intercourse. Conversely, more restrictive attitudes towards EDI (perceived severity, degree of perceived upset, and how detrimental it is perceived to be to the relationship) predicted greater difficulty but also greater obligation in disclosing all forms of EDI. Specific implications of these findings, including potential implications for therapy, are discussed. Overall, this study provides preliminary information regarding potentially useful factors to consider in understanding the EDI disclosure process that may also be useful in developing intervention points in therapy.
\end{abstract}

Keywords Infidelity $\cdot$ Affairs $\cdot$ Disclosure $\cdot$ Couples

R. B. Seedall (ه)

Marriage and Family Therapy Program, Utah State University, 2700 Old Main, Logan, UT, USA

e-mail: ryan.seedall@usu.edu

A. Houghtaling

Caron Treatment Centers, 243 North Galen Hall Road, Wernersville, PA, USA

E. J. Wilkins

Couple and Family Therapy, Drexel University, 3141 Chestnut Street, Philadelphia, PA, USA

Published online: 17 February 2013 


\section{An Overview of Extra-Dyadic Involvement}

Extra-dyadic involvement (EDI) is broadly defined as physical and/or emotional intimacy occurring outside the context of a committed relationship and without the knowledge or consent of one's partner (Allen and Baucom 2004). It has been a relatively difficult phenomenon to study, in part because of the secrecy and stigma that accompany it. It has also been relatively difficult to define, at least in ways that facilitate comprehensive empirical study. Two large-scale, nationally representative studies exist, each of which focused solely on sexual activity occurring outside of a marital relationship (extra-marital sex; EMS). Both studies yielded similar results, with somewhere between 11.6-15\% of women and 22.7-24.5\% of men reporting a lifetime prevalence of EMS averaged across all age groups (Laumann et al. 1994; Wiederman 1997). However, the prevalence increases substantially when expanding the definition of EDI to include emotional relationships, physical relationships not involving sexual intercourse, Internet-based relationships, and similar behaviors occurring outside of non-marital committed relationships, each of which share some dynamics with EMS (Parker and Wampler 2003).

The prevalence of EDI is particularly concerning considering its potentially deleterious interpersonal and intrapersonal effects, including depression, anxiety, obsessive rumination and hypervigilance, decreased trust, increased conflict, violent thoughts, and/or suicidal ideation (Glass 2000; Gordon et al. 2004). One study's findings also provide evidence of the systemic consequences of sexual EDI. Interestingly, even sexual EDI that had not been discovered by the partner was associated with greater demand-withdraw patterns during conflict discussions (Balderrama-Durbin et al. 2012). Sexual EDI also had the greatest predictive power of subsequent divorce - two times that of any other problem (Amato and Rogers 1997; see also Previti and Amato 2004). The severity and intensity of these effects are influenced by the length, type, and overall degree of EDI, the level of secrecy and betrayal, as well as a variety of pre-existing individual, relationship, and contextual factors (Allen and Atkins 2005; Blow and Hartnett 2005b; Humphrey 1987). In this manner, a variety of complex factors influence the breadth, depth, and intensity of EDI consequences.

In terms of clinical work with couples, the prevalence, complexity, and deleterious effects of EDI make it an especially salient issue. Therapist surveys have identified extramarital sex as a common reason (46\% of cases) given for seeking treatment (Humphrey 1987). Extra-marital affairs are also considered to have the second-most damaging impact on a marriage (behind physical abuse), and to be the third-most difficult issue to treat (behind lack of loving feelings and alcoholism; Whisman et al. 1997). Similarly, couples entering treatment primarily to address EDI issues are more distressed than those entering treatment for other reasons (Atkins et al. 2005; Atkins et al. 2010). Yet a recent survey of 332 MFTs found that a large majority of those sampled (74 \%) felt their training programs had inadequately prepared them to deal with EDI disclosure and treatment (Softas-Nall et al. 2008). A similar number (72\%) felt that the professional literature did not adequately address the topic.

\section{EDI Disclosure}

Empirical Research on EDI Disclosure

One factor that has been understudied in the EDI literature but that has potential to strongly influence the course individuals and relationships take in recovering from EDI is the 
timing, amount, and overall context to which EDI is disclosed (Blow and Hartnett 2005b; Humphrey 1987; Winek and Craven 2003). To this point, however, scholarly work and research has focused primarily on the role of the therapist in facilitating disclosure as well as identifying effective methods of treating couples following disclosure (c.f. Atkins et al. 2005; Butler et al. 2008, 2009; Gordon et al. 2004). Implicit within both of these areas is the idea that EDI disclosure is an influential process in working through the relationshipdisrupting effects of an EDI.

Unfortunately, little empirical attention has been given to understanding the individual and relationship characteristics related to any part of the process of EDI disclosure and its consequences (Allen et al. 2005). Only three studies were identified, with the first study examining the disclosure attitudes self-identified sexual addicts (Schneider and Corley 2002). In that sample, $57.9 \%$ of individuals who had engaged in extramarital involvement and $81.3 \%$ of their partners reported that they had initially felt that disclosure had been a positive thing. At the time of the survey, an even greater number (96.1\% involved; $93 \%$ partners) acknowledged that disclosure had been positive, and a substantial majority indicated that they would recommend disclosure to other couples (71\% of involved individuals and $82.7 \%$ of their partners who ultimately stayed together, and $65 \%$ of involved individuals and $87.5 \%$ of their partners who divorced; Schneider and Corley 2002). However, because the sample consisted of self-identified sexual addicts, it is unknown whether results can be generalized to couples where the EDI does not stem from a reported addiction.

The second study, examining a small sample of clinical couples $(n=19$; Atkins et al. 2005), found that couples where EDI had been disclosed were more distressed prior to treatment. However, those couples improved at a greater rate and ended at similar levels of dyadic adjustment when compared to couples where EDI was not an issue. The most recent study (Atkins et al. 2010), conducted in Germany and Austria, examined 145 clinical couples where infidelity was a presenting issue and compared them to 385 clinical couples not addressing infidelity. Findings from that study replicated the previous findings of Atkins et al. (2005) in terms of initial couple distress and ending at similar levels of dyadic adjustment compared to other couples.

\section{Theoretical Framework and Study Purpose}

These three empirical studies provide preliminary evidence regarding the importance of the disclosure process and the potential for couple therapy to help couples heal from EDI. In this manner, it is imperative that issues related to EDI disclosure be further addressed by empirical research in order to understand the disclosure process, including the role of therapy in working through EDI that has been disclosed and also in facilitating disclosure of EDI that is unknown to the other partner. In this study, we integrated the theory of planned behavior (TPB; Fishbein and Ajzen 2010) with social exchange theory (Nye 1982) to learn more about the potential factors involved in the decision to disclose. Although there are a number of relationship and other contextual factors that are likely associated with the overall disclosure process, the actual decision to disclose is an individual one. The theory of planned behavior (TPB; Fishbein and Ajzen 2010) explains that the interaction between attitudes, subjective norms (including norms established with the relationship), and perceived control influences intention that ultimately leads to behavior. With respect to EDI, this means that the decision to disclose occurs, based at least in part, upon the relationship among an individual's beliefs about EDI (attitudes), what individuals perceive they should do (subjective norms) and the perceived difficulty associated with the disclosure (behavioral control). 
In this study, we wanted to understand more about factors associated with the decision to disclose, including how attitudes towards EDI related to perceptions about the difficulty of disclosure (behavioral control) and the sense of responsibility to disclose (subjective norms). We used social exchange theory (SET) to conceptualize potential attitudes towards EDI. Social exchange theory (SET) explains that humans make conscious, rational choices in negotiating activities that involve the perceived benefits and/or costs of a particular behavior. These choices involve continual evaluation in an effort to maximize rewards and minimize costs in their interactions (Nye 1982). Although individual rewards and costs are usually emphasized within a SET framework, we include for the purposes of this study the idea of relationship rewards and costs, which are important considerations within close relationships.

In this study, we explored EDI attitudes in two ways: (a) permissive attitudes towards EDI (external, internal, and emotional justifications); and (b) restrictive attitudes towards EDI (the perceived risks/costs: how serious the specific act would be, how upset they would be, and how detrimental it would be to their relationship). We then estimated the relationship between these attitudes towards EDI and the subjective norms (i.e., perceived obligation) and behavioral control (i.e., perceived difficulty) associated with EDI disclosure. Overall, our primary research question was how permissive and restrictive attitudes towards EDI relate to perceptions of the difficulty to disclose as well as the obligation to disclose.

\section{Methods}

\section{Design and Participants}

This study used a correlational design to assess the attitudes, subjective norms, and perceived behavioral control associated with extra-dyadic involvement (EDI) and its disclosure. A total of 337 individuals (female: $n=240 ; 71.2 \%$; male: $n=97 ; 28.8 \%$ ), all of whom were enrolled in at least one university-level course, participated in this study. Participant ages ranged from 18 to 44 , with $93.7 \%(n=314)$ between the ages of 18 and 23. Nearly all were heterosexual $(98.5 \%, n=331)$ and had no children $(96.6 \%$, $n=316)$. A majority of participants were Euro-American $(79.5 \%, n=268)$, with small representation from other groups (American Indian/Alaskan Native: .3\%, $n=1$; Asian/ Pacific Islander: $1.5 \%, N=5$; African American: $6.8 \%, n=23$; Mexican-American/ Hispanic: $8.6 \%, n=29$; Multiracial: $1.8 \%, n=6$; and other: $1.5 \%, n=5$ ). Relatively equal proportions were single and dating $(47.9 \%, n=161)$ or single and not currently dating $(41.7 \%, n=140)$. Small numbers of respondents were either living together $(1.8 \%, n=6)$, engaged $(3.6 \%, n=12)$, or married $(3.9 \%, n=13)$. Despite a substantial minority of respondents not being in a committed relationship at the time of the survey, only $3.3 \%(n=11)$ reported never having been in a committed relationship. Regardless, all participants were asked to evaluate their responses within the context of a long-term, committed couple relationship.

\section{Procedures}

Following Institutional Review Board (IRB) approval, participants were recruited from classes at three universities in the Midwest $(n=202)$, Southeast $(n=126)$, and Northeast $(n=9)$ United States. Participants were recruited from several different social science 
classes at each university and represented majors from education, business, and the social and biological sciences. Instructors who invited their students to take part also agreed to (a) distribute the assessment packet during the final $15 \mathrm{~min}$ of one class period, and (b) provide extra credit for all those who completed the surveys. All responses were confidential and anonymous. Because assessments were distributed after the class lecture had ended, the students were free to leave if they chose not to complete the survey but were asked to complete demographic information. However, no demographic information was received without accompanying results from the remainder of the survey. Although it is possible that students may have left class without completing the demographic information or the survey, these results provide evidence that most, if not all, students in attendance participated in the study.

\section{Measures}

\section{Justification of Extramarital Involvement Questionnaire (JEIQ)}

The JEIQ is a 17-item, Likert (1-4) measure of justifications for engaging in extramarital relationships (Glass and Wright 1992). Participants rate a number of potential justifications along the continuum of "completely justified" to "completely unjustified." For the purposes of this study, the wording of the questionnaire was altered slightly. Whereas the original questionnaire referred to extra-marital involvement, the wording was adapted for this study to include any extra-dyadic emotional and/or sexual relationship outside of a long-term, committed relationship. With respect to reliability in this sample, the overall JEIQ measure had very high internal consistency for all respondents $(\alpha=.95)$ and separately for men $(\alpha=.96)$ and for women $(\alpha=.95)$.

\section{EDI Disclosure Index (EDIDI)}

The EDIDI was developed for the purposes of this study and consists of five Likert-based scales (1-5) that ranged from 11 to 13 items each (61 items total, $\alpha=.95$; see Table 1 for correlations between study variables). Scales assess the respondents' beliefs regarding a range of sexual, emotional, telephone, and Internet activity occurring outside the context of a long-term, committed relationship. The severity scale (13 items) presents individuals with a general situation where a man or women engages in an activity and asked participants how serious that action is in terms of a long-term, committed relationship's wellbeing. It demonstrated very high total internal consistency for this sample $(\alpha=.96)$, as well as for men $(\alpha=.94)$ and women $(\alpha=.97)$.

The upset scale (13 items) is a personalized adaptation of the severity scale. Respondents address how upset they would be if their partner, within the context of their own long-term committed relationship, engaged in various forms of EDI. The detrimental scale (13 items) is parallel to the upset scale. After individuals rate how upset they would be if their partner engaged in a particular emotional, sexual, telephone, and/or Internet EDI, respondents indicate how likely they would be to end their relationship. The internal consistency for both scales was high for men (upset: $\alpha=.90$; detrimental: $\alpha=.91$ ), women (upset: $\alpha=.94$; detrimental: $\alpha=.89$ ), and the total sample (upset: $\alpha=.89$; detrimental: $\alpha=.91$ ).

The final two scales of the EDIDI are related to beliefs about the disclosure of various forms of EDI. The disclosure difficulty scale (11 items) assesses a respondent's beliefs about the difficulty experienced in disclosing various forms of extra-dyadic activity to his/her partner. Participants then completed the disclosure obligation (11 items), which mirrored the 
Table 1 Bivariate correlations between variables

\begin{tabular}{|c|c|c|c|c|c|c|c|c|c|c|}
\hline & 1 & 2 & 3 & 4 & 5 & 6 & 7 & 8 & 9 & 10 \\
\hline \multicolumn{11}{|l|}{1} \\
\hline 2 & $.74 * * *$ & & & & & & & & & \\
\hline 3 & $.51 * * *$ & $.38 * * *$ & & & & & & & & \\
\hline 4 & $-.36 * * *$ & $-.24 * * *$ & $-.22 * * *$ & & & & & & & \\
\hline 5 & $.21 * * *$ & $-.26^{* * *}$ & $-.17 * *$ & $.16^{* *}$ & & & & & & \\
\hline 6 & $.40 * * *$ & $-.32 * * *$ & $-.33 * * *$ & $.35 * * *$ & $.34 * * *$ & & & & & \\
\hline 7 & $-.24 * * *$ & $-.23 * * *$ & $-.22 * * *$ & $.21 * * *$ & $.26 * * *$ & $.76^{* * *}$ & & & & \\
\hline 8 & $-.20 * * *$ & $-.21 * * *$ & $-.21 * * *$ & $.21 * * *$ & $.22 * * *$ & $.39 * * *$ & $.31 * * *$ & & & \\
\hline 9 & $-.25 * * *$ & $-.20 * * *$ & $-.28 * * *$ & $.21 * * *$ & .05 & $.48 * * *$ & $.42 * * *$ & $.55 * * *$ & & \\
\hline 10 & $-.14 *$ & $-.15^{* *}$ & $-.11 *$ & $.17 * *$ & $.26 * * *$ & $.17 * *$ & $.15^{* *}$ & $.37 * * *$ & $.19^{* *}$ & \\
\hline 11 & $-.32 * * *$ & $-.29 * * *$ & $-.26^{* * *}$ & $.24 * * *$ & .08 & $.58 * * *$ & $.51 * * *$ & $.36 * * *$ & $.44 * * *$ & $.44 * * *$ \\
\hline
\end{tabular}

Variable 1: justification-positive experience; Variable 2: justification-emotional intimacy; Variable 3: justification-external motivation; Variable 4: severity of EDI; Variable 5: degree of upset-EDI including sexual intercourse; Variable 6: Degree of upset-EDI not including sexual intercourse; Variable 7: how detrimental to the relationship; Variable 8: difficulty disclosing-sexual or personal EDI; Variable 9: difficulty disclosing - emotional or impersonal EDI; Variable 10: obligation-EDI including sexual intercourse; Variable 11: obligation-EDI not including sexual intercourse

$* p<.05 ; * * p<.01 ; * * * p<.001$

activities found on the ease of disclosure scale. Overall reliability for both scales was again high (ease: $\alpha=.88$; obligation: $\alpha=.91$ ), as was the internal consistency for men (ease: $\alpha=.88$; obligation: $\alpha=.90$ ) and women (ease: $\alpha=.88$; obligation: $\alpha=.90$ ).

\section{Results}

Preliminary Analyses

\section{Missing Data}

The issue of missing data was a relatively minor one, with the largest number of missing responses for any EDIDI scale being eight (2.4\%). Nonetheless, a majority of the items $(83.5 \%, n=66$ ) had only $0-3$ missing data points (less than $1 \%$ missing). For all missing data, values were imputed using Systat's EM Method for data imputation, which estimates values using maximum likelihood. Little's MCAR test statistic for each series of imputed values used in the remainder of this study's analyses was non-significant, indicating that the null hypothesis of data missing completely at random was retained.

\section{Exploratory Factor Analyses (EFA)}

Prior to testing the structural equation model, we wanted to examine the validity of the Justifications of Extramarital Involvement Questionnaire (JEIQ) and the EDI Disclosure Index (EDIDI) using exploratory factor analysis principal axis factoring. This allowed us to confirm the previously identified factors involved in justifying extra-dyadic involvement and also explore the factor structure of the newly developed EDIDI. In order to increase interpretability, factors for each measure were rotated using promax rotation, an orthogonal 
rotation that allows small correlations between factors in order to maximize fit between variables within each factor (Tabachnick and Fidell 2007). For each exploratory factor analysis, the Kaiser rule was used to guide decisions regarding the appropriate number of factors to extract.

\section{$J E I Q E F A$}

Three factors were extracted and their loadings rotated, accounting for $74.2 \%$ of the total variance (factor one $=57.5 \%$; factor two $=9.6 \%$; and factor three $=7.2 \%$; see Table 2 ) Once rotated, inter-factor correlations ranged from .36 (factors two and three) to .66 (factors one and two). The identified three factor structure is slightly different from the four factor model of EDI justification presented by Glass and Wright (1992), which set forth factors relating to a sexual dimension, emotional intimacy, extrinsic motivation, and a love dimension. The items corresponding to factors two and three in this sample are identical to the emotional intimacy and extrinsic motivation factors, respectively. However, factor one relates primarily to positive experience, including items related to both sex and love. Loadings for items corresponding to each factor ranged from .54 to 1.02 for positive external experiences, $.60-.98$ for emotional intimacy, and .83-.84 for extrinsic motivation. Two items did not achieve the .45 loading cutoff (Tabachnick and Fidell 2007) for any of the factors. Nonetheless, internal consistency remained moderate to high for the items in each factor (positive experience: $\alpha=.94$; emotional intimacy: $\alpha=.86$; and extrinsic motivation: $\alpha=.76$ ).

Table 2 EFA factor loadings for Justifications of Extramarital Involvement Questionnaire (JEIQ)
Bold values indicate those loadings above the .45 cut-off

\begin{tabular}{|c|c|c|c|}
\hline & $\begin{array}{l}\text { Factor 1: } \\
\text { positive } \\
\text { experience }\end{array}$ & $\begin{array}{l}\text { Factor 2: } \\
\text { emotional } \\
\text { intimacy }\end{array}$ & $\begin{array}{l}\text { Factor 3: } \\
\text { extrinsic } \\
\text { motivation }\end{array}$ \\
\hline 1. For fun & .57 & .25 & .14 \\
\hline 2. For intellectual sharing & .10 & .79 & -.07 \\
\hline 3. For a romantic experience & .94 & .04 & -.15 \\
\hline 4. To feel young & .44 & .25 & .25 \\
\hline $\begin{array}{l}\text { 5. To relieve sexual } \\
\text { deprivation or frustration }\end{array}$ & .74 & -.01 & .25 \\
\hline $\begin{array}{l}\text { 6. For someone to understand } \\
\text { problems and feelings }\end{array}$ & -.16 & .98 & -.03 \\
\hline 7. To enjoy sexual relations & 1.02 & -.15 & .04 \\
\hline $\begin{array}{l}\text { 8. For sexual experimentation } \\
\text { or curiosity }\end{array}$ & .90 & -.12 & .16 \\
\hline 9. For companionship & .47 & .60 & -.27 \\
\hline 10. For sexual excitement & .98 & -.18 & .13 \\
\hline 11. To get love and affection & .60 & .42 & -.19 \\
\hline $\begin{array}{l}\text { 12. To enhance self-confidence } \\
\text { and self-esteem }\end{array}$ & .17 & .63 & .19 \\
\hline 13. For novelty and change & .25 & .41 & .34 \\
\hline 14. To be respected & -.29 & .93 & .25 \\
\hline $\begin{array}{l}\text { 15. Falling in love with another } \\
\text { person }\end{array}$ & .54 & .36 & -.22 \\
\hline 16. To get even with partner & .01 & .01 & .84 \\
\hline 17. To advance my career & .07 & -.02 & .83 \\
\hline
\end{tabular}




\section{EDIDI EFA}

An exploratory factor analysis with a promax rotation was also performed on all of the items of the EDIDI in order to gain an overall view of the factor structure and verify that items loaded appropriately on each of the scales (severity, degree of upset, how detrimental to the relationship, difficulty disclosing, and obligation to disclose). The EDIDI loaded on 11 factors, accounting for $75.6 \%$ of total variance (see Table 3). We then analyzed each factor to understand whether items from each of the subscales loaded together. With respect to severity, all items but confiding in and hugging a friend achieved the .45 cutoff, ranging from .61 to .95 . For the degree of upset subscale, all items but one (having lunch with a coworker and sharing personal information) primarily loaded on two factors (factor 1: EDI involving sexual intercourse; factor 2: EDI not involving sexual intercourse), ranging from .45 to .85 . Three items that referred to direct sexual intercourse loaded on the second factor. For the detrimental to the relationship subscale, all items but one (having sex with multiple individuals) loaded on one factor, ranging from .52 to .84 . All items for the difficulty disclosing subscale loaded on two factors (factor 1: physical and personal EDI; factor 2: emotional and impersonal EDI) and ranged from .49 to .88. Lastly, all items for the obligation to disclose subscale loaded on two factors (factor 1: EDI involving sexual intercourse; factor 2: EDI not involving sexual intercourse). Overall, the EFA provided preliminary evidence for the validity of the EDIDI, with each of its subscales clustering around one or two factors, primarily related to differing types of EDI. When items of a subscale clustered around two factors, separate values for each factor were retained and entered into the primary analyses.

Table 3 EFA factor loadings for EDI Disclosure Index (EDIDI)

\begin{tabular}{|c|c|c|c|c|c|c|c|c|}
\hline \multirow[t]{2}{*}{ Item } & \multirow{2}{*}{$\begin{array}{l}\text { EDI severity } \\
\text { F1 }\end{array}$} & \multicolumn{2}{|c|}{$\begin{array}{l}\text { EDI } \\
\text { upset }\end{array}$} & \multirow{2}{*}{$\begin{array}{l}\text { EDI detrimental } \\
\text { F3 }\end{array}$} & \multicolumn{2}{|c|}{$\begin{array}{l}\text { Disclosure } \\
\text { difficulty }\end{array}$} & \multicolumn{2}{|c|}{$\begin{array}{l}\text { Disclosure } \\
\text { obligation }\end{array}$} \\
\hline & & F5 & F9 & & $\mathrm{F} 4$ & F11 & $\mathrm{F} 2$ & F8 \\
\hline Chat-sexual topics & .92 & .06 & .75 & .74 & .70 & .43 & .82 & .44 \\
\hline Confide and hug & .39 & .10 & .45 & .52 & & & & \\
\hline Chat-personal info, flirt & .72 & .16 & .74 & .75 & & & & \\
\hline Porn/masturbation & .78 & .04 & .51 & .58 & .37 & .49 & .79 & .23 \\
\hline Flirting and confiding & .61 & .05 & .41 & .57 & .53 & .68 & .73 & .17 \\
\hline Make out w/old friend & .90 & .48 & .65 & .73 & & & & \\
\hline Cybersex & .93 & .29 & .83 & .84 & .76 & .35 & .79 & .56 \\
\hline Sex-friend & .85 & .85 & .40 & .64 & .85 & .19 & .31 & .92 \\
\hline Pornography & .81 & .16 & .57 & .68 & .18 & .51 & .81 & .20 \\
\hline Sex-prostitute & .92 & .80 & .11 & .53 & .86 & .20 & .27 & .91 \\
\hline Strip club & .88 & .17 & .53 & .67 & .52 & .45 & .75 & .40 \\
\hline Telephone sex & .95 & .30 & .74 & .77 & .88 & .32 & .77 & .58 \\
\hline Sex-mult. individuals & & .82 & .27 & .41 & & & & \\
\hline Oral sex & .92 & & & & .83 & .35 & .50 & .82 \\
\hline Flirting & & & & & .32 & .83 & .70 & .01 \\
\hline
\end{tabular}

Bold values indicate those loadings above the .45 cut-off 
Structural Equation Model

\section{The Hypothesized Model}

A structural equation model (SEM) was used to estimate the relationship among attitudes, subjective norms, and perceived behavioral control associated with EDI and its disclosure. Our model (Fig. 1) consisted of two second-order latent variables (permissive and restrictive attitudes towards EDI) and four first order manifest variables (difficulty disclosing physical and personal EDI, difficulty disclosing emotional and impersonal EDI, obligation to disclose EDI related to sexual intercourse, and obligation to disclose EDI not related to sexual intercourse). The indicators for permissive EDI attitudes were how positive the EDI experience was perceived, the emotional intimacy involved, or the extrinsic motivation to engage in EDI. The indicators for restrictive EDI attitudes were the overall perceived severity of EDI, how upset they would be about EDI involving sexual intercourse, how upset they would be about EDI not involving sexual intercourse, and how detrimental EDI would be to their relationship.

\section{Model Estimation}

Because it is fairly robust against potentially non-normal data, maximum likelihood estimation was performed using Mplus for all model estimation. The independence model hypothesizing that all variables were uncorrelated was rejected, $\chi^{2}(55, n=336)=1,416$, $p<.001$. A Chi square difference test found that the hypothesized model, $\chi^{2}$ (33, $n=336)=131, \quad p<.001 ; \quad$ CFI $=.93 ; \quad$ RMSEA $=.09 \quad(90 \% \quad$ CI $=.077 ; \quad .111)$; SRMR $=.06$, represented a significant improvement in fit over the independence model. Overall, the CFI and SRMR values provided evidence of a good fitting model. However, RMSEA values were in the commonly accepted range indicating mediocre fit (MacCallum et al. 1996). Despite these somewhat contrasting results, we concluded that the model yielded reasonable fit.

\section{Direct Effects}

More permissive attitudes towards EDI, as indicated by justifications of EDI, were not significantly associated with the level of disclosure difficulty for physical/personal (unstandardized coefficient $=-.06, p=.26$ ) or emotional/impersonal (unstandardized coefficient $=-08, p=.18$ ) EDI. More permissive attitudes were also not significantly associated with the perceived obligation to disclose sexual intercourse (unstandardized coefficient $=-.07, p=.16$ ). However, it was significantly associated with the perceived obligation to disclose EDI that did not include sexual intercourse (unstandardized coefficient $=-.12, p=.03$ ), meaning that those individuals with permissive attitudes towards EDI were less likely to feel obligated to disclose EDI that did not include sexual intercourse.

More restrictive attitudes towards EDI, as indicated by identifying greater costs and consequences, were significantly associated with the level of disclosure difficulty for physical/personal (unstandardized coefficient $=.66, p<.001$ ) and emotional/impersonal (unstandardized coefficient $=.92, p=.26$ ). Similarly, they were also significantly associated with the perceived obligation to disclose sexual intercourse (unstandardized coefficient $=.21, p=.03$ ) and EDI that did not involve sexual intercourse (unstandardized coefficient $=1.13, p<.001$ ). In this manner, greater perceived costs associated with EDI were associated with greater difficulty disclosing but also greater obligation to disclose. 


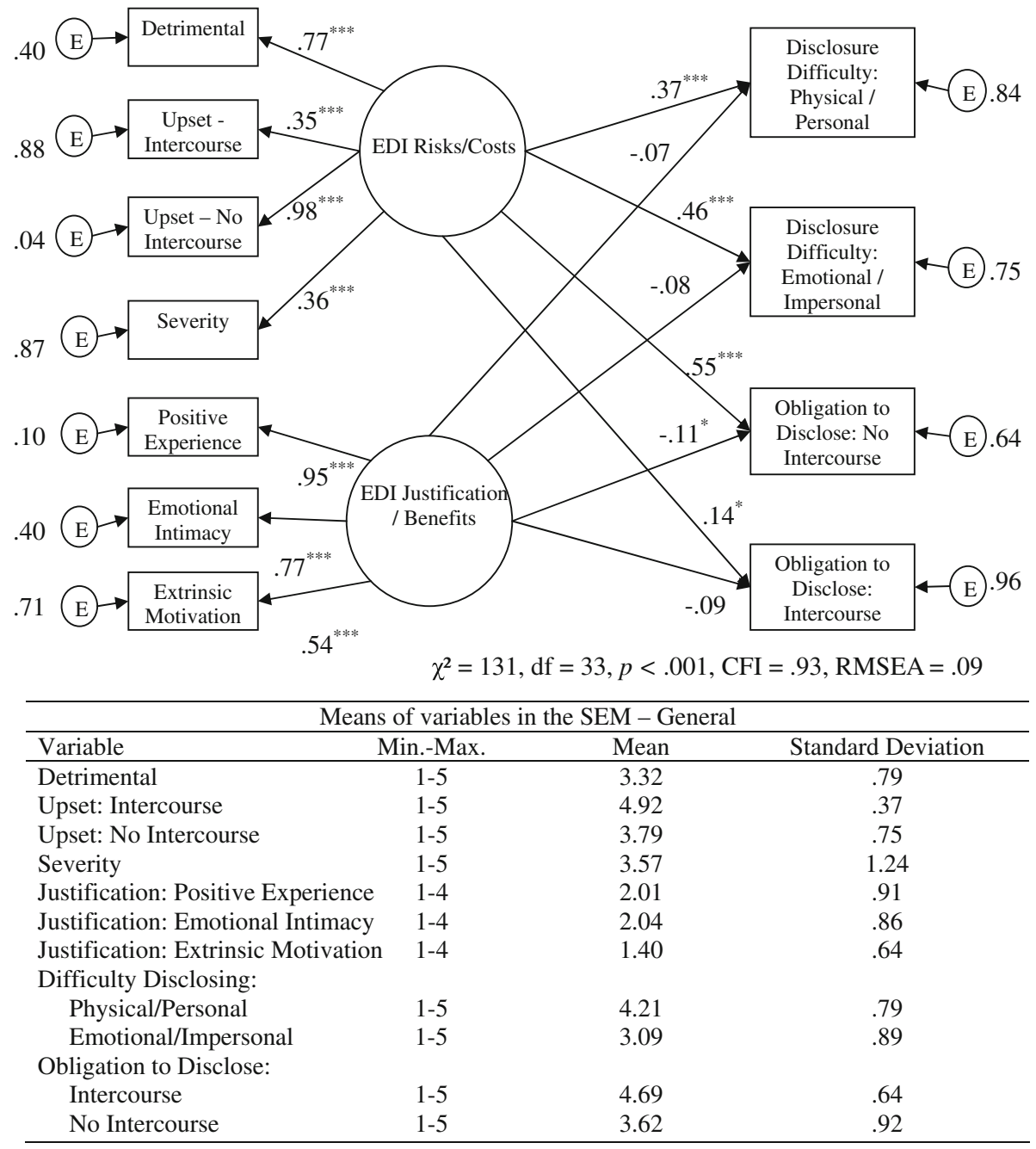

Fig. 1 Hypothesized structural equation model (standardized values)

\section{Discussion}

Extra-dyadic involvement (EDI) of some kind affects a substantial number of relationships and contributes to a variety of relationship dynamics that can be difficult for couples. For that reason, EDI and its effects are common issues in therapy. Although EDI issues have been increasingly studied in research, the disclosure process has been understudied. In this study, we sought an understanding of some factors that are likely to influence one aspect of the disclosure process, the decision to disclose EDI. Specifically, we used the theory of planned behavior (TPB; Fishbein and Ajzen 2010) to analyze the relationship between restrictive attitudes towards EDI (how severe, upsetting, and detrimental) as well as more permissive attitudes (justifications related to positive experience, emotional intimacy, and external motivation) with perceived norms (felt obligation) and behavioral control 
(perceived difficulty) associated with its disclosure. Our findings provide preliminary empirical evidence that attitudes towards EDI as well as subjective norms and perceived behavioral control regarding EDI disclosure are important factors in the decision to disclose.

\section{Justifications of EDI}

Our findings revealed that more permissive attitudes towards EDI were not associated with the perceived behavioral control (i.e., perceived difficulty) associated with disclosure of any type of EDI behavior. They were also not associated with subjective norms (i.e., the obligation to disclose) associated with disclosure of EDI involving sexual intercourse. In other words, more permissive attitudes towards EDI were not related to the perceived difficulty of disclosure or the obligation to disclose EDI involving sexual intercourse. In this manner, it may be more plausible that permissive attitudes towards EDI influence its continuation rather than its disclosure.

However, more permissive attitudes were associated with subjective norms associated with disclosure of EDI that did not involve direct sexual intercourse with another person, with more permissive attitudes associated with less obligatory feelings. This provides evidence that individuals may have different subjective norms for EDI that does not involve sexual intercourse, including that it is not as necessary to disclose. These attitudes may be perceived by the partner as active concealment in an effort to ensure that positive consequences associated with the EDI continue, leading to a greater sense of betrayal and more disruptive relationship dynamics if the EDI is discovered by the partner (rather than disclosed).

\section{Costs/Consequences of EDI}

In contrast, more restrictive attitudes related to EDI, especially related to its potential negative consequences, were associated with greater difficulty and more obligatory feelings to disclose EDI. Interestingly, these more restrictive attitudes did not vary based upon the type of EDI (i.e., involving sexual intercourse or not). These findings may point toward a potential dichotomy: the greater the perceived obligation to disclose something, the more difficult it is to disclose. Within an individualistic ethic that emphasizes the importance of maximizing rewards and minimizing costs, the idea that perceived obligation to disclose is associated with greater difficulty represents a dichotomy.

However, a relational ethic presupposes that individuals in close relationships seek to achieve an "oscillating balance among family members, whereby basic life interests of each are taken into account by others," thereby leading to mutually satisfying benefits (Boszormenyi-Nagy et al. 1991, p. 204; see also Butler et al. 2009). EDI both highlights and introduces complex power dynamics within close relationships (Lammers et al. 2011; Williams 2011) that often imbalance the relationship between partners and thereby violate relational ethics. In this manner, these findings may point towards the reality that an individual may know s/he needs to disclose the EDI (as part of a relational ethic that will begin the process of regaining an appropriate balance of give and take) but also recognizes that disclosing will greatly hurt the other person. Regardless of whether an individual or relationship ethic (or some combination of the two) is the driving force, these findings provide evidence that attitudes regarding the negative consequences of EDI are likely to lead to interplay between subjective norms and perceived behavioral control. 
From a clinical perspective of working with couples where EDI has occurred, understanding these three factors (attitudes towards EDI; and subjective norms and perceived behavioral control regarding EDI disclosure) may yield valuable insight into (a) effective ways of exploring the disclosure process and it effects on relationship dynamics; or (b) to facilitate disclosure if the EDI is still unknown to the other partner. The following sections will discuss potential therapeutic implications related to these three factors within both of these contexts.

\section{Facilitating Exploration of Previous Disclosure}

Understanding that part of the decision to disclose involves attitudes about EDI and perceptions about subjective norms and behavioral control regarding disclosure opens up some interesting intervention points in therapy. An early stage of the treatment process is working with the volatility and overall individual and relationship disruption that typically accompanies discovery of EDI (Gordon et al. 2005) in an effort to facilitate a safe, validating therapeutic environment in which to foster healing (Williams 2011). Although a variety of precipitating factors may exist in the actual disclosure or discovery of EDI (i.e., individual, partner, relationship, and contextual factors; Allen et al. 2005), an important step towards meaning-making is exploring the attitudes and beliefs of both partners regarding EDI and its disclosure.

A thorough, thoughtful exploration of attitudes and beliefs provides a valuable context for healing. For example, if the EDI was disclosed by the involved partner, it might be useful to explore how that person arrived at the decision to disclose, including relevant thoughts and feelings that made it possible. In addition, exploring the partner's attitudes and beliefs about EDI and disclosure can help foster an increased sense of responsibility in the involved partner regarding the consequences of the EDI. Conversely, if the EDI was discovered or only partially disclosed, exploring that decision with the involved partner and the consequences for the other person can be useful in helping the therapist assess the overall effects of EDI on individual and relationship functioning while also facilitating perspective-taking and a greater emphasis on the relational ethics involved (Butler et al. 2008, 2009). This is especially useful for involved partners who have a great deal of relationship power and exhibit a general pattern of emphasizing their own needs at the expense of their partner's (i.e., an individual ethic).

\section{Facilitating Previously Unknown Disclosure}

Exploring the attitudes and beliefs that were examined in this study can also be useful when the EDI has not been disclosed. The ethical issues involved in this process, including the various options that exist for therapists, has been explored in-depth elsewhere (e.g., Butler et al. 2008, 2009; Snyder and Doss 2005). As a result, we will not address this decision-making process here. Rather, we will briefly discuss how the exploration of attitudes relating to EDI and beliefs about the norms and behavioral control associated with disclosure can be useful when working to help facilitate disclosure. In this manner, it can be useful to understand the EDI justifications influencing the decision to disclose, trace the consequences of disclosure versus non-disclosure, and validate the potential challenges of disclosing. Understanding perceptions about norms and behavioral control associated with EDI and disclosure can provide useful information regarding the interplay between each as 
well as the role of guilt and shame in the process. Overall, a respectful and empathetic exploration of these areas can be useful in helping address important individual and relational issues regarding disclosure. It can also be especially important in moving beyond a focus on individual needs (individual ethic) to include a relational ethic, which emphasizes the partner's experiences and needs as important considerations in achieving relational balance (Boszormenyi-Nagy et al. 1991; Butler et al. 2009).

\section{Limitations of This Study}

Although this study yielded some valuable findings, it is not without its limitations. Despite a fairly large sample and efforts to counterbalance the effects of non-randomization by gathering data from three geographically distinct universities, we do not know to what extent our findings can be generalized to a broader population of married couples. Nonetheless, our primary focus in this study was to explore potential factors involved in the decision to disclose. We acknowledge that many aspects of the EDI disclosure process may be strongly influenced by relationship and other contextual factors. However, our goal was to explore more general attitudes and perceptions regarding EDI and its disclosure that individuals may carry into their long-term committed relationships. Our findings provide preliminary evidence that attitudes about EDI, subjective norms associated with EDI disclosure, and the perceived behavioral control associated with EDI disclosure each play a role in the decision to disclose. Although each may also be influenced, at least in part, by contextual factors, we are confident that these are important factors to explore when processing the disclosure experience or facilitating disclosure with couples. Regardless, we encourage future research to use random sampling techniques with other samples to further understand these relationships.

In addition, this study utilized prospective self-reports for its findings where participants responded to hypothetical situations (e.g., as if they or their partners had engaged in EDI). Concerns have been raised regarding the association between prospective reports and the actual experience of EDI (Blow and Hartnett 2005a; Harris 2002). Although explained previously that the attitudes of college students towards EDI and its disclosure are useful in helping understand the factors involved in the decision to disclose, it is essential that future research use retrospective accounts contextualized by specific individual and relationship characteristics to understand additional elements involved in the process of EDI disclosure. In a similar vein, we did not assess previous participant experiences with EDI, something which might have influenced their responses and should be investigated in future research. These findings should be considered tentative until further research addresses these potential limitations.

\section{Implications for Future Research}

Despite these limitations, our study's implications regarding EDI disclosure are valuable and provide an impetus for future research to replicate and expand upon these findings. In terms of understanding the interplay between subjective norms and perceived behavioral control, it is possible that specific intrapersonal and interpersonal factors contribute to which of the two (subjective norms or perceived behavioral control) is given primary importance above the other to ultimately lead to disclosure or non-disclosure. Future research will need to investigate this relationship further.

We also strongly encourage future research to investigate the additional factors that may be involved in the timing and process of EDI disclosure. These might include individual 
characteristics, situational variables, motivational factors, and characteristics of the involved person's partner. For example, research will need to identify what individual characteristics increase the likelihood of disclosure and how suspicion by the involved person's partner as well as other partner factors may also influence disclosure (Allen 2001; Allen et al. 2005). Similarly, specific situational variables and motivational factors that facilitate disclosure need to be identified. It is also important to understand the factors involved in the disclosure process that most strongly influence individual and couple distress as well as their ultimate recovery trajectory. Research in each of these areas is needed to further understand the disclosure process and inform clinical work with couples who have experienced EDI.

\section{Conclusion}

Overall, this study represents a first step toward more fully understanding the process of EDI disclosure and the factors involved in the decision to disclose. It also provides evidence that attitudes, subjective norms, and perceived behavioral control all play a potentially important part in the decision to disclose and provide valuable insight into factors that may be involved in the disclosure process as well as potentially useful intervention points in exploring or facilitating disclosure in therapy. It also points towards the need for more research to gain greater breadth and depth of understanding regarding all potential factors that lead to or inhibit the disclosure. This understanding will ultimately enhance clinical work with couples in terms of how to help facilitate disclosure as well as understanding which variables associated with disclosure (e.g., individual characteristics, situational variables, motivational factors, and characteristics of the involved person's partner) most strongly influence treatment process and outcome.

\section{References}

Allen, E. S. (2001). Attachment styles and their relation to patterns of extradyadic and extramarital involvement. Unpublished doctoral dissertation, University of North Carolina, Chapel Hill.

Allen, E. S., \& Atkins, D. C. (2005). The multidimensional and developmental nature of infidelity: Practical applications. Journal of Clinical Psychology, 61, 1371-1382. doi:10.1002/jclp.20187.

Allen, E. S., Atkins, D. C., Baucom, D. H., Snyder, D. K., Gordon, K. C., \& Glass, S. P. (2005). Intrapersonal, interpersonal, and contextual factors in engaging in and responding to extramarital involvement. Clinical Psychology: Science and Practice, 12, 101-130. doi:10.1093/clipsy.bpi014.

Allen, E. S., \& Baucom, D. H. (2004). Adult attachment and patterns of extradyadic involvement. Family Process, 43, 467-488. doi:10.1111/j.1545-5300.2004.00035.x.

Amato, P. R., \& Rogers, S. J. (1997). A longitudinal study of marital problems and subsequent divorce. Journal of Marriage and the Family, 59, 612-624.

Atkins, D. C., Eldridge, K. A., Baucom, D. H., \& Christensen, A. (2005). Infidelity and behavioral couple therapy: Optimism in the face of betrayal. Journal of Consulting and Clinical Psychology, 73, 144-150. doi:10.1037/0022-006X.73.1.144.

Atkins, D. C., Marín, R. A., Lo, T. T. Y., Klann, N., \& Hahlweg, K. (2010). Outcomes of couples with infidelity in a community-based sample of couple therapy. Journal of Family Psychology, 24, 212-216.

Balderrama-Durbin, C. M., Allen, E. S., \& Rhoades, G. K. (2012). Demand and withdraw behaviors in couples with a history of infidelity. Journal of Family Psychology, 26, 11-17. doi:10.1037/a0026756.

Blow, A. J., \& Hartnett, K. (2005a). Infidelity in committed relationships I: A methodological review. Journal of Marital and Family Therapy, 31, 183-2005. doi:10.1111/j.1752-0606.2005.tb01555.x.

Blow, A. J., \& Hartnett, K. (2005b). Infidelity in committed relationships II: A substantive review. Journal of Marital and Family Therapy, 31, 217-233. doi:10.1111/j.1752-0606.2005.tb01556.x. 
Boszormenyi-Nagy, I., Grunebaum, J., \& Ulrich, D. (1991). Contextual therapy. In A. S. Gurman \& D. P. Kniskern (Eds.), Handbook of family therapy (Vol. 2). New York: Brunner/Mazel.

Butler, M. H., Harper, J. M., \& Seedall, R. B. (2009). Facilitated disclosure versus clinical accommodation of infidelity secrets: An early pivot point in couple therapy. Part 1: Couple relationship ethics, pragmatics, and attachment. Journal of Marital and Family Therapy, 35, 125-143. doi:10.1111/j.17520606.2008.00106.x.

Butler, M. H., Seedall, R. B., \& Harper, J. M. (2008). Facilitated disclosure vs. clinical accommodation of infidelity secrets: An early pivot point in couple therapy. Part 2: Therapy ethics, pragmatics, and protocol. American Journal of Family Therapy, 36, 265-283. doi:10.1080/01926180701291253.

Fishbein, M., \& Ajzen, I. (2010). Predicting and changing behavior: The reasoned action approach. New York, NY: Psychology Press.

Glass, S. P. (2000). Infidelity. AAMFT Clinical Update, 2, 1-8.

Glass, S. P., \& Wright, T. L. (1992). Justifications for extramarital relationships: The associations between attitudes, behavior, and gender. The Journal of Sex Research, 29, 361-387.

Gordon, K. C., Baucom, D. H., \& Snyder, D. K. (2004). An integrative intervention for promoting recovery from extramarital affairs. Journal of Marital and Family Therapy, 30, 213-231. doi:10.1111/ j.1752-0606.2004.tb01235.x.

Gordon, K. C., Baucom, D. H., \& Snyder, D. K. (2005). Treating couples recovering from infidelity: An integrative approach. Journal of Clinical Psychology, 61, 1393-1405. doi:10.1002/jclp.20189.

Harris, C. R. (2002). Sexual and romantic jealousy in heterosexual and homosexual adults. Psychological Science, 13, 7-12. doi:10.1111/1467-9280.00402.

Humphrey, F. G. (1987). Treating extramarital sexual relationships in sex and couples therapy. In G. R. Weeks \& L. Hot (Eds.), Integrating sex and marital therapy: A clinical guide (pp. 149-170). New York: Brunner/Mazel.

Lammers, J., Stoker, J. I., Jordan, J., Pollmann, M., \& Stapel, D. A. (2011). Power increases infidelity among men and women. Psychological Science, 22, 1191-1197. doi:10.1177/0956797611416252.

Laumann, E., Gagnon, J., Michael, R., \& Michaels, S. (1994). The social organization of sexuality: Sexual practices in the United States. Chicago: University of Chicago Press.

MacCallum, R. C., Browne, M. W., \& Sugawara, H. M. (1996). Power analysis and determination of sample size for covariance structure modeling. Psychological Methods, 1, 130-149.

Nye, F. I. (1982). The basic theory. In F. I. Nye (Ed.), Family relationships: Rewards and costs (pp. 13-31). Beverly Hills, CA: Sage.

Parker, T. S., \& Wampler, K. S. (2003). How bad is it? Perceptions of the relationship impact of internet sexual activities. Contemporary Family Therapy, 25, 415-429. doi:10.1023/A:1027360703099.

Previti, D., \& Amato, P. R. (2004). Is infidelity a cause or a consequence of poor marital quality? Journal of Social and Personal Relationships, 21, 217-230. doi:10.1177/0265407504041384.

Schneider, J. P., \& Corley, M. D. (2002). Disclosure of extramarital sexual activities by persons with addictive or compulsive sexual disorders. In P. Carnes \& K. M. Adams (Eds.), Clinical management of sex addiction (pp. 137-161). New York: Routledge.

Snyder, D. K., \& Doss, B. D. (2005). Treating infidelity: Clinical and ethical directions. Journal of Clinical Psychology, 61, 1453-1465. doi:10.1002/jclp.20194.

Softas-Nall, B., Beadle, M., Newell, J., \& Helm, H. M. (2008). Spousal disclosure of extramarital relationships: Attitudes of marriage and family therapists. The Family Journal: Counseling and Therapy for Couples and Families, 16, 328-337. doi:10.1177/1066480708323203.

Tabachnick, B. G., \& Fidell, L. S. (2007). Using multivariate statistics (5th ed.). Boston: Allyn and Bacon.

Whisman, M. A., Dixon, A. E., \& Johnson, S. (1997). Therapists' perspectives of couple problems and treatment issues in couple therapy. Journal of Family Psychology, 11, 361-366.

Wiederman, M. W. (1997). Extramarital sex: Prevalence and correlates in a national survey. Journal of Sex Research, 34, 167-174.

Williams, K. (2011). A socio-emotional relational framework for infidelity: The relational justice approach. Family Process, 50, 516-528. doi:10.1111/j.1545-5300.2011.01374.x.

Winek, J. L., \& Craven, P. A. (2003). Healing rituals for couples recovery from adultery. Contemporary Family Therapy, 25, 249-266. doi:10.1023/A:1024518719817. 